\title{
Pitfalls in surveillance for hepatocellular carcinoma: How successful is it in the real world?
}

\author{
Linda L. Wong ${ }^{1,2}$, Ruel J. Reyes ${ }^{3}$, Sandi A. Kwee ${ }^{4}$, Brenda Y. Hernandez ${ }^{2}$, Sumodh C. Kalathil ${ }^{5}$, and Naoky C. Tsai ${ }^{5}$ \\ 'Department of Surgery, University of Hawaii, John A. Burns School of Medicine; ${ }^{2}$ Cancer Center, University of Hawaii; ${ }^{3}$ University of \\ Hawaii, John A. Burns School of Medicine; ${ }^{4}$ Positron Emission Tomography Imaging Research and ${ }^{5}$ Liver Center, The Queen's Medical \\ Center, Honolulu, HI, USA
}

Background/Aims: Surveillance for hepatocellular carcinoma (HCC) with ultrasound in high-risk populations is generally believed to improve opportunities for treatment. However, tumors are still missed due to various factors. This study explores success versus failure of $\mathrm{HCC}$ surveillance.

Methods: This is a retrospective study of 1,125 HCC cases. Categories considered for successful detection were largest tumor $\leq 3.0 \mathrm{~cm}$, single tumors $\leq 3.0 \mathrm{~cm}$ and $\leq 2.0 \mathrm{~cm}$, and adherence to Milan criteria. Examined factors were age $<60$ years, gender, rural residence, body-mass index (BMI), hepatitis infection, smoking, diabetes, hyperlipidemia, cirrhosis, ascites, and Model for End-Stage Liver Disease $<10$.

Results: HCC was found on surveillance in 257 patients with a mean tumor size of $3.17 \mathrm{~cm}$; multiple tumors were seen in $28 \%$ of cases, bilateral tumors in $7.4 \%$, and vascular invasion in $3.7 \%$. Surveillance was successful in $61.5 \%$ of cases involving a largest tumor $\leq 3.0 \mathrm{~cm}$, with $\mathrm{BMI} \geq 35$ negatively affecting detection (odds ratio [OR] $0.28, P=0.014$ ) and cirrhosis positively affecting detection (OR 2.31, $P=0.036$ ). Ultrasound detected $19.1 \%$ of single tumors $\leq 2.0 \mathrm{~cm}$ with ascites improving the detection rate (OR 3.89, $P=0.001)$. Finally, adherence to Milan criteria occurred in $75.1 \%$ of cases, revealing negative associations with diabetes (OR $0.48, P=0.044$ and male gender (OR $0.49, P=0.08$ ).

Conclusions: Although surveillance is recommended for HCC, not all surveillance ultrasound are ideal. Tumor detection can depend on gender, BMI, diabetes, cirrhosis, and ascites and is achieved in $19.1-75 \%$ of cases depending on the definition of success. Closer follow-up or additional imaging might be necessary for some patient subgroups. (Clin Mol Hepatol 2017;23:239-248)

Keywords: Carcinoma; Hepatocellular; Early detection of cancer; Population surveillance; Ultrasonography

\section{INTRODUCTION}

Hepatocellular carcinoma (HCC) is the second most common cause of cancer death worldwide and the incidence and mortality of this cancer continue to increase in the United States., ${ }^{1,2}$ In the United States, liver cancer death rates are rising faster than that of any other cancer site. ${ }^{2}$ Most of these cancers were historically attributed to viral Hepatitis B and C, but the epidemic of diabetes,

\section{Abbreviations:}

AFP, alpha-fetoprotein; BMI, body-mass index; CT, computed tomography; HCC, hepatocellular carcinoma; MELD, Model for End-Stage Liver Disease; MRI, magnetic resonance imaging; NASH, non-alcoholic steatohepatitis; OR, odds ratio; SD, standard deviation; US, ultrasound.

\section{Corresponding author : Linda L. Wong}

Department of Surgery, University of Hawaii John A. Burns School of Medicine, 550 South Beretania Street, Suite 403 Honolulu, HI 96813, USA

Tel: +1-808-523-5033, Fax: +1-808-528-4940

E-mail:hepatoma@aol.com

http://orcid.org/0000-0003-3143-5384 
obesity, metabolic syndrome and fat-related liver disease will likely sustain the prevalence of this cancer in the future. ${ }^{2}$ Unfortunately, many patients with HCC present at an advanced stage or with poor underlying liver function and will not qualify for curative treatments. While survival with HCC is modestly improving, the overall 5-year survival still remains quite dismal at $17.8 \%{ }^{3}$ Early identification of liver cancer is the key to improved survival. In addition to a large, randomized prospective study demonstrated the benefit of surveillance for HCC, numerous retrospective studies have reported prolonged survival in those patients who had their cancer found with surveillance., ${ }^{4,5}$ Despite the limited rigor- ous data, surveillance for HCC has become an accepted practice by most hepatologists. ${ }^{6}$ Current guidelines by various gastroenterology and hepatology societies recommend surveillance of high risk groups using ultrasound (US) with the goal of detecting small lesions while curative options are still possible. ${ }^{7,8}$

While US has become the established standard, there are wide variations in the quality of sonography that is performed. ${ }^{9}$ US is highly operator dependent and requires patient cooperation for optimal studies. Patient factors such as body habitus and ultrasound equipment including probes, resolution, and equipment all contribute to the quality of the study. Specialized centers and

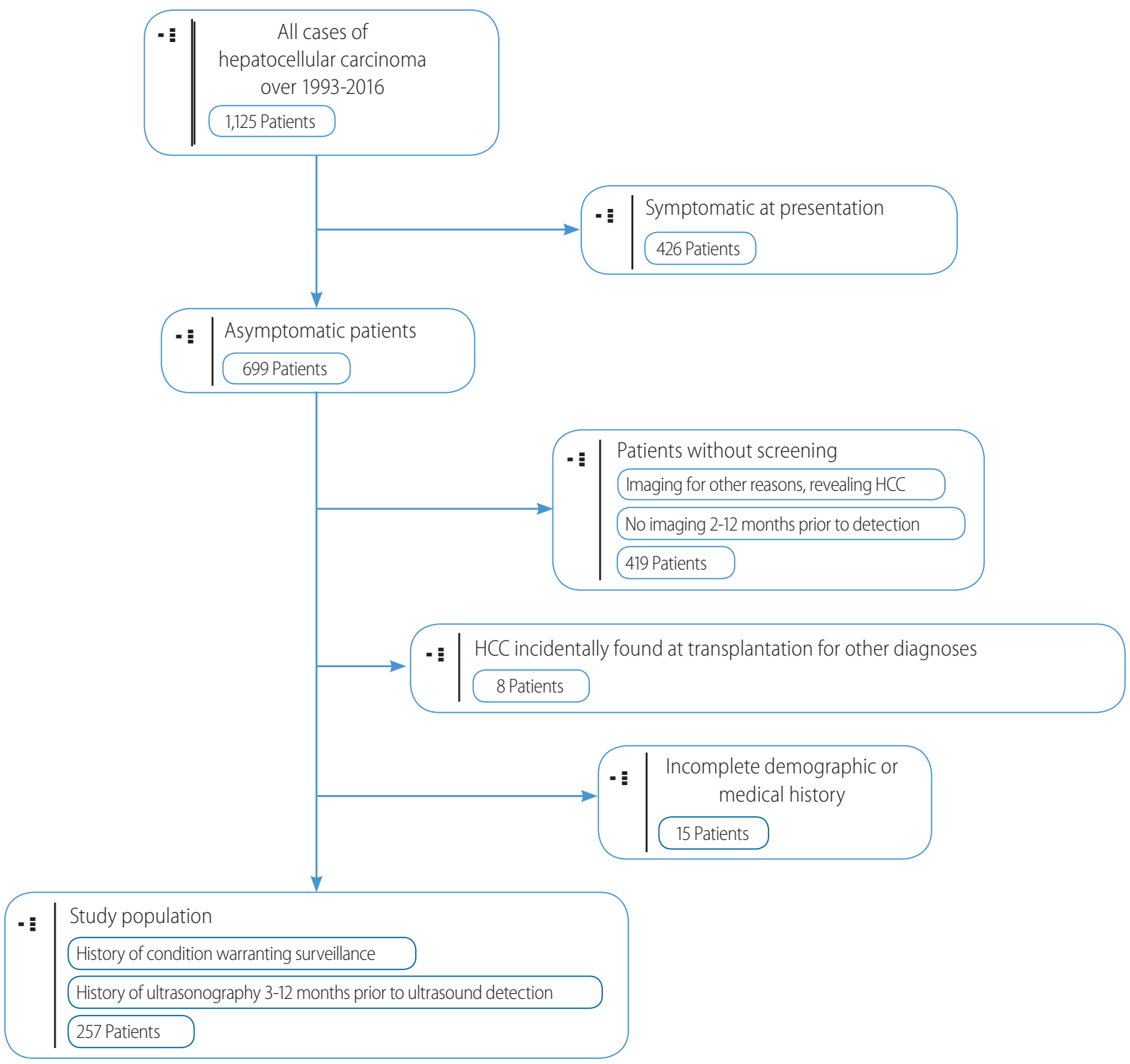

Figure 1. Patient selection criteria. Inclusion and exclusion criteria used to select patient cases for this study. Patients were required to have at least. one surveillance ultrasound prior to detection. Patients were excluded if ultrasound was performed less than 3 months or greater than 12 months prior to detection, symptoms were present warranting imaging, and if tumors were incidentally found on imaging. 
transplant centers who frequently perform liver specific-US may have different quality from sonography units in small hospitals and private imaging centers. ${ }^{10}$ Finally, recent advances in US may have improved the detection rate of small HCC when compared to technology used to establish the surveillance guidelines.

In this study, we examined a large prospectively collected database to assess the effectiveness of US surveillance to detect early HCC. As there is no established definition for successful US surveillance, we have used several criteria as follows: (1) Milan Criteria, (2) Largest tumor $<3 \mathrm{~cm}$, (3) Single tumor $<3 \mathrm{~cm}$, and (4) Single tumor $<2 \mathrm{~cm}$ and also attempt to identify factors that impact upon successful surveillance.

\section{PATIENTS AND METHODS}

This is a retrospective analysis of 1,125 HCC cases referred over a 24-year period (1993-2016) to our group of physicians who are associated with only liver transplant program in Hawaii and the only referral center for liver disease/surgery for American territories of the Pacific Basin (including Samoa, Guam, Saipan, and the Marshall Islands). This clinic and the transplant center were initially affiliated with Hawaii Medical Center-East (formerly St. Francis Medical Center) and after 2012, the Queens Medical Center. This center sees about $60-70 \%$ of the HCC cases in Hawaii.

In the early years, HCC was diagnosed histologically by percutaneous biopsy or at surgery. In the first decade and consistent with the previous United Network for Organ Sharing policy regarding transplant for HCC, patients without histologic confirmation were included if they had a history of chronic liver disease and a mass at least $2 \mathrm{~cm}$ in size seen on two imaging studies (ultrasound, CT scan or MRI) and one of the following: (1) vascular blush seen on CT scan or MRI, (2) Alpha-feto protein (AFP) $>200 \mathrm{ng} / \mathrm{mL}$ or (3) arteriogram confirming the tumor." More recently, the diagnosis of HCC was made with only imaging if a contrast-enhanced study (dynamic CT or MRI) showed typical arterial enhancement with "washout" in the venous phase as described by the American Association for the Study of Liver Disease guidelines. ${ }^{7,8}$

Identifying data were removed prior to abstraction by study investigators. Information on demographics, medical history, laboratory results, tumor characteristics, treatment, and survival was collected via clinical interview. Demographic data included age, sex, birthplace, and the patient's self-reported ethnicity. Ethnicity was then categorized as "White", "Asian", or "Pacific Islander." Patients who did not fit into one of these categories or were of mixed ethnicity were subsequently classified as "Other." Patients of mixed race with at least $50 \%$ Pacific Islander ethnicity were categorized as "Pacific Islander". As a surrogate for urban versus rural location of surveillance ultrasound performed, we used Oahu (island with largest population, Honolulu and the larger tertiary referral centers) vs non-Oahu (Big Island, Maui, Kauai, Molokai and Lanai). Data collected on medical history included diabetes mellitus, hyperlipidemia, smoking, and risk factors for HCC including viral hepatitis, alcohol abuse (defined as greater than two alcoholic beverages daily for at least ten years), and other chronic liver diseases. Patients were also classified as having hyperlipidemia if lipid-lowering agents were present on their medication list. Information was based on available medical records and interview by a single physician. Measured height and weight were used to determine body mass index (BMI).

Laboratory data collected included bilirubin, albumin, prothrombin time, creatinine, alanine aminotransferase, aspartate aminotransferase, platelet count, and AFP. Laboratory data that was used for the study had been obtained within 2 weeks of initial visit. Bilirubin, prothrombin time with international normalized ratio and creatinine were used to calculate the Model for Endstage Liver Disease (MELD) score. Hepatitis B positivity included those with who had a positive hepatitis B surface antigen and hepatitis $C$ positivity included those who had a positive hepatitis C antibody, irrespective of viral RNA level. The size, number, and location of the tumor(s) was used to determine the Tumor Node Metastases (TNM) stage according to the American Joint Commission on Cancer staging manual. ${ }^{12}$

The proportion of patients with HCC detected by surveillance was noted. Although our Liver Center recommends that community physicians perform surveillance US and AFP every 6 months in patients with viral hepatitis and chronic liver disease who meet American Association for the Study of Liver Diseases (AASLD) criteria for surveillance, there was no uniform protocol used in the cohort. Referring physicians used a combination of AFP and/or US at variable intervals. As surveillance intervals differed amongst patients due to a number of factors including lack of physician awareness/adherence of current surveillance guidelines, and patient compliance, we included patients with US-detected HCC with a history of at least one negative ultrasound prior to detection. Patients who were symptomatic at initial presentation were excluded from this study.

HCC was deemed to be found on "surveillance" if the patient had a previous US from three to twelve months prior, showing no liver masses. Patients with surveillance intervals less than 3 
months or greater than 12 months were excluded from this study. In cases where previous US reports were unavailable, we used physicians notes or presenting US reports indicating a previous US investigation. Initial detection of HCC by CT or MRI was not considered surveillance, and these patients were excluded from this study. Additionally, cases of incidental HCC found on the explanted liver at transplant were also excluded (Fig. 1).

Since there is no standardized definition for successful surveillance, we used several potential definitions including detection of the following lesions: Largest tumor $\leq 3.0 \mathrm{~cm}$, Single tumor $\leq 3.0$ $\mathrm{cm}$, Single tumor $\leq 2.0 \mathrm{~cm}$ and $\mathrm{HCC}$ meeting Milan criteria (single tumor $<5 \mathrm{~cm}$ or $2-3$ tumors all $<3.0 \mathrm{~cm}$ ). For each of these groups, we compared categorical values of age $<60$ years vs. $\geq 60$ years, male vs. female, urban vs. non-urban, hepatitis B positive vs. negative, hepatitis $C$ positive vs. negative, BMI $\geq 25$ vs. $<25$ $\mathrm{kg} / \mathrm{m}^{2}, \mathrm{BMI} \geq 30 \mathrm{vs} .<30 \mathrm{~kg} / \mathrm{m}^{2}, \mathrm{BMI} \geq 35 \mathrm{vs} .<35 \mathrm{~kg} / \mathrm{m}^{2}$, smoking vs. non-smoking, diabetes vs. no diabetes, hyperlipidemia vs. no hyperlipidemia, presence of ascites vs. no ascites, presence of cirrhosis vs. no cirrhosis, and MELD $\geq 10$ vs. $<10$. Data analysis was performed with SPSS Statistics (version 24, IBM Corp., Armonk, NY, USA). Multiple logistic regression was used to calculate odds ratios and $95 \%$ confidence intervals. Statistical significance was determined to be a $P$-value of $<0.05$.

This study was approved by the University of Hawaii Institutional Review Board. This study was conducted in accordance with institutional and federal regulations for the protection of human subjects.

\section{RESULTS}

\section{Patient characteristics}

Of the 1,125 patients with HCC, 865 had diagnoses which prompted HCC surveillance, including hepatitis B, hepatitis C, alcoholic cirrhosis, or cirrhosis due to autoimmune hepatitis or non-alcoholic steatohepatitis (NASH). Of this group, 271 (31.3\%) patients underwent appropriate ultrasound surveillance. Fourteen patients were excluded due to incomplete height and weight data used to calculate BMI. The mean age of 257 patients within this study cohort was 62 years (standard deviation [SD] \pm 9.4 ) and $69.6 \%$ were males. Sixty-eight patients resided and were referred from practices on rural neighbor islands, whereas 189 were followed on Oahu. More than half of the patients were Asian. With regards to disease etiology: 119 patients (61.9\%) had hepatitis C, 78 patients $(30.3 \%)$ had hepatitis B, 8 patients (3.1\%) were co-infected with hepatitis B and C, 16 patients (6.2\%) had NASH, 12 patients (4.7\%) had alcoholic cirrhosis without viral risk factors, and 3 patients (1.2\%) had autoimmune hepatitis. Mean BMI was 26.8 (range 16.0-49.8, SD 5.55). Other comorbidities included hypertension in 126 patients (49.0\%), diabetes in 88 patients (34.2\%), and hyperlipidemia in 44 patients (17.1\%). MELD score was less than 10 in 142 patients (55.3\%) and 118 patients (45.9\%) had AFP less than $20 \mathrm{ng} / \mathrm{mL}$. Ascites was present in 51 (19.8\%) patients with 2 of these having intractable ascites requiring frequent paracentesis. Please see Table 1 for further details.

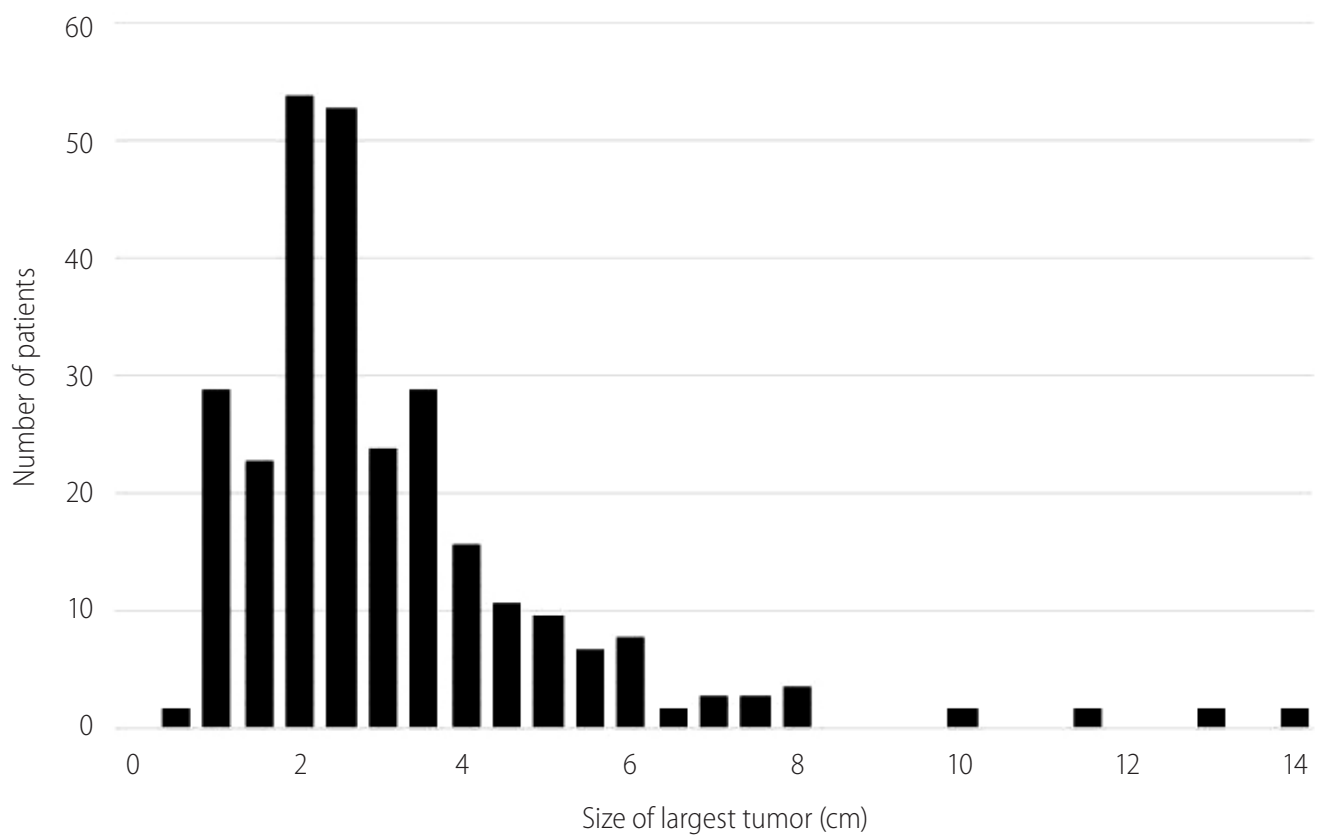

Figure 2. Tumor size distribution upon detection. Most tumors were detected between 1.3-5.0 $\mathrm{cm}$. However, tumors larger than $5 \mathrm{~cm}$ and up to $14 \mathrm{~cm}$ were detected despite prior negative ultrasound(s). 
Table 1. Patient profiles $(n=257)$

\begin{tabular}{|c|c|}
\hline Characteristic & Value \\
\hline Mean age in years (range) & $62.2(38-89)$ \\
\hline Age <60 (n, \%) & $113(44)$ \\
\hline Male (n, \%) & $179(69.6)$ \\
\hline \multicolumn{2}{|l|}{ Ethnicity (n, \%) } \\
\hline Asian & $143(55.6)$ \\
\hline Caucasian & $64(24.9)$ \\
\hline Pacific Islander & $37(14.4)$ \\
\hline African American & $6(2.3)$ \\
\hline Other & $7(2.7)$ \\
\hline Oahu $(n, \%)$ & $189(73.5)$ \\
\hline BMI (range, SD) & $26.8(16.0-49.8,5.5)$ \\
\hline $\mathrm{BMI}>25(\mathrm{n}, \%)$ & $151(58.8)$ \\
\hline $\mathrm{BMI}>30(\mathrm{n}, \%)$ & $54(21.0)$ \\
\hline $\mathrm{BMI}>35(\mathrm{n}, \%)$ & $22(8.6)$ \\
\hline \multicolumn{2}{|l|}{ Etiology of disease (n, \%) } \\
\hline $\mathrm{HCV}$ & $159(61.9)$ \\
\hline HBV & $78(30.3)$ \\
\hline NASH & $16(6.2)$ \\
\hline Alcoholic cirrhosis & $11(4.3)$ \\
\hline Autoimmune hepatitis & $2(0.8)$ \\
\hline Hereditary Hemochromatosis & $1(0.4)$ \\
\hline Human immunodeficiency virus & $1(0.4)$ \\
\hline PCT & $1(0.4)$ \\
\hline Smoking (n, \%) & $156(60.7)$ \\
\hline Alcohol history (n, \%) & $110(42.8)$ \\
\hline Diabetes (n, \%) & $88(34.2)$ \\
\hline Cirrhosis (n, \%) & $221(86.0)$ \\
\hline \multicolumn{2}{|l|}{ Ascites (n, \%) } \\
\hline No ascites & $205(79.8)$ \\
\hline Moderate ascites & $49(19.1)$ \\
\hline Severe ascites & $2(0.8)$ \\
\hline \multicolumn{2}{|l|}{ MELD Score } \\
\hline Mean MELD score (SD) & $10.1(3.43)$ \\
\hline Range (n, \%) & $6.43-25.0$ \\
\hline$<10$ & $151(58.8)$ \\
\hline $10.0-19.9$ & $100(38.9)$ \\
\hline $20.0-29.9$ & $3(1.2)$ \\
\hline \multicolumn{2}{|l|}{ CTP Score } \\
\hline Range & $5.0-13.0$ \\
\hline
\end{tabular}

Table 1. Continued

\begin{tabular}{|c|c|}
\hline Characteristic & Value \\
\hline Mean (SD) & $6.26(1.69)$ \\
\hline Class A (5-6 points) (n, \%) & $172(66.9)$ \\
\hline Class B (7-9 points) (n, \%) & $68(26.5)$ \\
\hline Class C (10-15 points) (n, \%) & $14(5.44)$ \\
\hline \multicolumn{2}{|l|}{ BCLC Staging $(n, \%)$} \\
\hline Stage 0 & $18(7.0)$ \\
\hline Stage A1 & $49(19.1)$ \\
\hline Stage A2 & $24(9.3)$ \\
\hline Stage A3 & $22(8.6)$ \\
\hline Stage A4 & $26(10.1)$ \\
\hline Stage B & $44(17.1)$ \\
\hline Stage C & $11(4.3)$ \\
\hline Stage D & $4(1.6)$ \\
\hline \multicolumn{2}{|l|}{ TNM Stage (AJCC 2015) (n, \%) } \\
\hline Stage I & $181(70.4)$ \\
\hline Stage II & $59(23.0)$ \\
\hline Stage Illa & $8(3.1)$ \\
\hline Stage IIIb & $9(3.5)$ \\
\hline Stage IV & $0(0)$ \\
\hline
\end{tabular}

$\mathrm{BMI}$, body mass index; SD, standard deviation; HCV, viral hepatitis $\mathrm{C} ; \mathrm{HBV}$, viral hepatitis B; NASH, non-alcoholic steatohepatitis; PCT, porphyria cunea tarda; MELD, Model for End-Stage Liver Disease Score; CTP, Child-TurcottePugh Score; BCLC, Barcelona Clinic Liver Cancer Staging; TNM, Tumor Node Metastasis Staging; AJCC, American Joint Committee on Cancer.

\section{Tumor characteristics}

Patients in this cohort presented upon surveillance with a mean largest tumor size of $3.14 \mathrm{~cm}$ (range $0.7-14 \mathrm{~cm}, \mathrm{SD} 1.83$ ). Figure 2 shows the distribution of the largest tumor identified with $27 \mathrm{pa}-$ tients presenting with tumors greater than $5.0 \mathrm{~cm}$, the maximum size allowed for single lesions under Milan Criteria. Multiple tumors were present in 72 patients $(28.0 \%)$ and in this group, the largest tumor had a mean size of $3.0 \mathrm{~cm}(\mathrm{SD} 1.59 \mathrm{~cm})$. Nineteen patients presented with more than 3 tumors, and 2 patients presented with diffuse HCC. Twenty patients (8.7\%) had bilateral liver involvement. Evidence of vascular invasion was present in 9 cases (3.5\%), and there were no cases of metastatic disease or tumor rupture.

\section{Detection vs. Surveillance failure}

Four definitions of successful detection were evaluated in this 
Table 2. Factors affecting successful detection of largest tumors $\leq 3.0 \mathrm{~cm}$ and tumors adhering to the Milan criteria with surveillance ultrasound

\begin{tabular}{|c|c|c|c|c|}
\hline & \multicolumn{2}{|c|}{ Largest tumor $\leq 3 \mathrm{~cm}(\mathrm{n}=158)$} & \multicolumn{2}{|c|}{ Meets Milan criteria $(n=193)$} \\
\hline & Odds ratio $(95 \% \mathrm{Cl})$ & $P$-value & Odds ratio $(95 \% \mathrm{Cl})$ & $P$-value \\
\hline Age $\leq 60(\%)$ & $0.79(0.48-1.32)$ & 0.37 & $0.67(0.38-1.17)$ & 0.16 \\
\hline Male gender (\%) & $0.62(0.35-1.08)$ & 0.09 & $0.44(0.22-0.89)$ & 0.02 \\
\hline Oahu (\%) & $1.49(0.85-2.62)$ & 0.16 & $1.24(0.66-2.32)$ & 0.50 \\
\hline HBV (\%) & $1.09(0.63-1.88)$ & 0.77 & $1.15(0.62-2.15)$ & 0.66 \\
\hline HCV (\%) & $1.09(0.65-1.83)$ & 0.74 & $1.05(0.59-1.88)$ & 0.86 \\
\hline BMI $25 \geq(\%)$ & $0.77(0.46-1.29)$ & 0.32 & $0.89(0.50-1.58)$ & 0.68 \\
\hline BMI $30 \geq(\%)$ & $0.55(0.30-1.01)$ & 0.051 & $0.83(0.42-1.63)$ & 0.58 \\
\hline BMI $35 \geq(\%)$ & $0.32(0.13-0.80)$ & 0.01 & $0.55(0.22-1.37)$ & 0.19 \\
\hline Smoking (\%) & $0.74(0.44-1.25)$ & 0.26 & $0.49(0.26-0.92)$ & 0.02 \\
\hline Diabetes (\%) & $0.99(0.59-1.69)$ & 0.98 & $0.63(0.35-1.13)$ & 0.12 \\
\hline Hyperlipidemia (\%) & $0.99(0.51-1.94)$ & 0.99 & $0.86(0.41-1.79)$ & 0.69 \\
\hline Ascites (\%) & $1.17(0.62-2.22)$ & 0.62 & $1.71(0.78-3.72)$ & 0.18 \\
\hline MELD 10 (\%) & $1.09(0.66-1.83)$ & 0.08 & $1.02(0.57-1.82)$ & 1.00 \\
\hline Cirrhosis (\%) & $1.97(0.97-4.01)$ & 0.058 & $1.19(0.54-2.62)$ & 0.67 \\
\hline
\end{tabular}

$\mathrm{Cl}$, confidence interval; HBV, viral hepatitis B; HCV, viral hepatitis C; BMI, body mass index; MELD, Model for End-Stage Liver Disease Score $>10$.

study: (1) meets Milan Criteria (2) largest tumor $\leq 3.0 \mathrm{~cm}$, (3) single tumor $\leq 3.0 \mathrm{~cm}$, (4) single tumor $\leq 2.0 \mathrm{~cm}$.

Of the patients who had HCC found on surveillance, 193 (75.1\%) patients met Milan Criteria. In this group, male gender was associated with poor detection as 52 of 64 male patients exceeding Milan Criteria were of male sex (OR 0.44, 95\% Cl 0.22$0.89 ; P=0.02$ ). Positive smoking history was also associated with poor detection within Milan Criteria with OR 0.49 (95\% Cl 0.260.92; $P=0.02$ ) (Table 2). After multiple logistic regression analysis, male sex remained associated with poor detection within Milan Criteria, however significance was marginal (OR 0.49, 95\% Cl 0.21-1.06; $P=0.080)$. Diabetes was also revealed to be associated with poor detection with Milan Criteria (OR 0.48, 95\% Cl 0.24$0.98 ; P=0.044)$. No other variables were found to have statistical significance (Table 3).

If the largest tumor was $\leq 3.0 \mathrm{~cm}$ used as the criteria, then 158 (61.5\%) patients had successful surveillance. BMI $\geq 35$ was associated with poor detection with Largest Tumor $\leq 3 \mathrm{~cm}$ (OR 0.28, $95 \% \mathrm{Cl} 0.10-0.76, P=0.014)$. However, the presence of cirrhosis correlated with improved detection with a Largest Tumor $\leq 3 \mathrm{~cm}$ (OR 2.31, 95\% Cl 1.06-5.13; $P=0.036$ ). No other variables were found to have statistical significance (Table 2, 3).

Of the entire cohort, 121 patients presented with a single tumor $\leq 3.0 \mathrm{~cm}$ resulting in a detection rate of $47.1 \%$. None of the variables evaluated were associated with successful surveillance, even after performing multiple logistic regression analysis (Table 4).

If single tumor $\leq 2.0 \mathrm{~cm}$ is the proposed criteria for successful surveillance, then 49 (19.1\%) patients had success. In this group, $\mathrm{BMI} \geq 25$ and $<30$ was associated with poor detection of single tumors $<2 \mathrm{~cm}(\mathrm{OR} 0.45,95 \% \mathrm{Cl} 0.20-0.98 ; P=0.050)$. However, the presence of ascites was associated with improved detection even after accounting for interactions using multiple logistic regression analsyis (OR 2.70, 95\% Cl 1.35-5.41; $P=0.004)$. See Tables 3 and 4 for details.

\section{DISCUSSION}

Multiple retrospective studies and one large randomized controlled trial have demonstrated the value of US surveillance in improving survival in HCC., ${ }^{4,13-15}$ Even after adjusting for lead-time bias, multiple studies have confirmed a survival benefit with surveillance. ${ }^{5,16-20}$ Studies have addressed the accuracy of US with a meta-analysis of 6 studies showing the pooled sensitivity and specificity for detection of HCC was $95 \%$ and $91 \%$ respectively. ${ }^{21}$ However, few studies have addressed the effectiveness of US surveillance in the detection of a specific size or number of tumors. If the goal of surveillance is to find HCC that would qualify for potentially curative therapy, it is imperative that we not only find HCC at surveillance but also find smaller tumors. Diagnosing ad- 
Linda L. Wong, et al.

Table 3. Significant associations after multiple logistic regression analysis

\begin{tabular}{|c|c|c|c|c|c|c|c|c|}
\hline & \multicolumn{2}{|c|}{$\begin{array}{l}\text { Meets Milan criteria } \\
\qquad(n=193)\end{array}$} & \multicolumn{2}{|c|}{$\begin{array}{l}\text { Largest tumor } \leq 3 \mathrm{~cm} \\
\qquad(\mathrm{n}=158)\end{array}$} & \multicolumn{2}{|c|}{$\begin{array}{l}\text { Single tumor } \leq 3 \mathrm{~cm} \\
\qquad(n=121)\end{array}$} & \multicolumn{2}{|c|}{$\begin{array}{l}\text { Single tumor } \leq 2 \mathrm{~cm} \\
\qquad(\mathrm{n}=49)\end{array}$} \\
\hline & $\begin{array}{l}\text { Odds ratio } \\
(95 \% \mathrm{Cl})\end{array}$ & $P$-value & $\begin{array}{l}\text { Odds ratio } \\
(95 \% \mathrm{Cl})\end{array}$ & $P$-value & $\begin{array}{l}\text { Odds ratio } \\
(95 \% \mathrm{Cl})\end{array}$ & $P$-value & $\begin{array}{l}\text { Odds-ratio } \\
(95 \% \mathrm{Cl})\end{array}$ & $P$-value \\
\hline Male gender & $0.49(0.21-1.06)$ & 0.080 & $0.64(0.33-1.23)$ & 0.187 & $0.93(0.50-1.72)$ & 0.805 & $0.89(0.41-1.98)$ & 0.771 \\
\hline \multicolumn{9}{|l|}{ BMI (ref: <25) } \\
\hline$\geq 25$ and $<30$ & $1.17(0.58-2.41)$ & 0.658 & $0.92(0.49-1.73)$ & 0.804 & $0.84(0.46-1.51)$ & 0.556 & $0.45(0.20-0.98)$ & 0.050 \\
\hline$\geq 35$ & $0.78(0.27-2.37)$ & 0.656 & $0.28(0.10-0.76)$ & 0.014 & $0.47(0.16-1.26)$ & 0.142 & $0.73(0.18-2.37)$ & 0.619 \\
\hline Smoking & $0.68(0.32-1.40)$ & 0.303 & $0.88(0.48-1.64)$ & 0.693 & $0.69(0.38-1.24)$ & 0.220 & $1.19(0.56-2.56)$ & 0.659 \\
\hline Diabetes & $0.48(0.24-0.98)$ & 0.044 & $0.93(0.49-1.75)$ & 0.822 & $1.01(0.55-1.84)$ & 0.0977 & $1.78(0.84-3.77)$ & 0.133 \\
\hline Ascites & $2.02(0.84-5.35)$ & 0.132 & $0.96(0.46-2.02)$ & 0.911 & $1.79(0.89-3.65)$ & 0.103 & 3.89 (1.69-9.12) & 0.001 \\
\hline Cirrhosis & $1.27(0.51-2.99)$ & 0.597 & $2.31(1.06-5.13)$ & 0.036 & $1.24(0.58-2.70)$ & 0.584 & $0.79(0.31-2.19)$ & 0.626 \\
\hline
\end{tabular}

$\mathrm{Cl}$, confidence interval; $\mathrm{BMI}$, body mass index.

Table 4. Factors affecting successful detection of single tumor $\leq 2.0 \mathrm{~cm}$ with surveillance ultrasound

\begin{tabular}{|c|c|c|c|c|}
\hline & \multicolumn{2}{|c|}{ Single tumor $\leq 2 \mathrm{~cm}(\mathrm{n}=49)$} & \multicolumn{2}{|c|}{ Single tumor $\leq 3 \mathrm{~cm}(n=121)$} \\
\hline & Odds-ratio $(95 \% \mathrm{Cl})$ & $P$-value & Odds ratio $(95 \% \mathrm{Cl})$ & $P$-value \\
\hline Age $\leq 60(\%)$ & $1.05(0.56-1.96)$ & 0.88 & $0.82(0.50-1.34)$ & 0.42 \\
\hline Male gender (\%) & $0.88(0.45-1.71)$ & 0.70 & $0.79(0.46-1.34)$ & 0.37 \\
\hline Oahu (\%) & $1.00(0.49-2.02)$ & 0.99 & $1.00(0.58-1.75)$ & 1.00 \\
\hline HBV (\%) & $1.02(0.52-2.00)$ & 0.97 & $0.95(0.56-1.62)$ & 0.84 \\
\hline HCV (\%) & $1.08(0.57-2.05)$ & 0.82 & $1.08(0.65-1.79)$ & 0.77 \\
\hline BMI $25 \geq(\%)$ & $0.68(0.36-1.27)$ & 0.22 & $0.77(0.47-1.26)$ & 0.30 \\
\hline BMI $30 \geq(\%)$ & $1.11(0.53-2.35)$ & 0.78 & $0.66(0.36-1.21)$ & 0.18 \\
\hline BMI $35 \geq(\%)$ & $0.94(0.30-2.91)$ & 0.91 & $0.50(0.20-1.26)$ & 0.13 \\
\hline Smoking (\%) & $1.02(0.54-1.92)$ & 0.96 & $0.69(0.41-1.14)$ & 0.14 \\
\hline Diabetes (\%) & $1.42(0.75-2.69)$ & 0.28 & $1.04(0.62-1.74)$ & 0.88 \\
\hline Hyperlipidemia (\%) & $0.77(0.32-1.85)$ & 0.56 & $1.29(0.67-2.46)$ & 0.45 \\
\hline Ascites (\%) & $2.70(1.35-5.41)$ & 0.004 & $1.79(0.96-3.33)$ & 0.07 \\
\hline MELD 10 (\%) & $0.94(0.50-1.76)$ & 0.87 & $1.11(0.68-1.83)$ & 0.71 \\
\hline Cirrhosis (\%) & $0.97(0.40-2.37)$ & 0.95 & $1.29(0.63-2.63)$ & 0.48 \\
\hline
\end{tabular}

$\mathrm{Cl}$, confidence interval; $\mathrm{HBV}$, viral hepatitis $\mathrm{B} ; \mathrm{HCV}$, viral hepatitis C; BMI, body mass index; MELD, Model for End-Stage Liver Disease Score $>10$.

vanced tumors with surveillance might infer that there was a failure in the previous study to detect HCC.

Initial detection of HCC through CT, MRI, or via pathological diagnosis poses a vulnerability to lead-time bias, which may inflate failure rates of surveillance ultrasound. This is particularly apparent when smaller tumors are detected on CT/MRI, which would otherwise be missed on ultrasound imaging. To reduce lead-time bias, patients with HCC detected through these other methods were excluded from this study.

This study proposed 4 possible criteria with US success rates of
19.1-75.1\% based on various criteria delineated. Although $75 \%$ of patients met Milan criteria at detection, when challenged to detect single tumors smaller than $3.0 \mathrm{~cm}$, US was successful less than $50 \%$ of the time. In one of the few studies exploring surveillance failure, Del Poggio, et al found that $81 \%$ of 1,170 patients with HCC met Milan criteria upon detection with surveillance. Dynamic imaging was subsequently performed and only $65.6 \%$ of this cohort actually met Milan criteria, thus yielding a 34.3\% failure rate of surveillance after complete staging. Sex, surveillance interval, Child-Pugh class and AFP >200 ng/mL were associated 
with surveillance failure. Similar to our study, only $20 \%$ of their cohort had a tumor less than $2 \mathrm{~cm}$ found with surveillance and the etiology of cirrhosis did not affect surveillance failure. ${ }^{22}$

Obesity may affect the accuracy of surveillance US for HCC. In this study morbidly obese patients with $\mathrm{BMI} \geq 35$ fared worse in detection of HCC with largest tumor $\leq 3 \mathrm{~cm}$ when compared to a reference population of $\mathrm{BMI}<25$. Del Poggio, et al found that $\mathrm{BMI}>25$ was associated with surveillance failure but only one fifth of their patients had BMI reported. ${ }^{22}$ In the Hepatitis C Antiviral Long-Term Treatment Against Cirrhosis (HALT-C) trial which investigated long-term outcome of patients who received interferon-based therapy for hepatitis $C$, rates of HCC detection did not differ between those with $\mathrm{BMI} \leq 30$ (64.4\%) compared to those with $\mathrm{BMI}>30(52.6 \%)$ in the 1,005 patients who underwent surveillance. ${ }^{23}$ Obesity and coarse texture of the liver pose challenges for ultrasound due to limited penetration of sonographic beams and increased attenuation resulting in poor image quality. ${ }^{24} \mathrm{MRI}$ or CT may be more appropriate for HCC surveillance in these patients due to improved image resolution and superior sensitivity. ${ }^{25}$ Patients with $\mathrm{BMI} \geq 25$ and $<30$ had poorer detection of single tumors $\leq 2.0 \mathrm{~cm}$. However, this result was based on 38 cases and with significance just being met a $P=0.05$. Conflicting results with respect to $\mathrm{BMI}$ and detection, may suggest that BMI may not be the optimal measurement to assess obesity. Thickened adipose tissue in the abdominal wall or truncal obesity would present great difficulty for the ultrasonographer. Increased waist circumference may be the more appropriate indicator for suboptimal ultrasound as this would take into account differences in body habitus, age, gender and ethnicity. ${ }^{26}$

Diabetes may also represent an independent risk factor in the development of HCC as discussed by Davila, et al. This study compared HCC cases with non-cancer controls and demonstrated a 2 to 3-fold increase in HCC incidence in diabetic patients after accounting for demographics and risk factors. ${ }^{27}$ Our study showed a similar trend, but instead examined HCC patients only and compared performance, with diabetic patients having poor detection of tumors within Milan Criteria. This may be related to the higher incidence of obesity resulting in poor detection using surveillance ultrasound. Despite this association, it remains unclear whether diabetes should be factored when considering alternatives to current surveillance recommendations. More investigation is necessary to further characterize the effects of diabetes on the success of ultrasound surveillance.

Gender differences may also affect the success of surveillance US. It is well described that women are more likely to attend health events and undergo cancer screening so compliance with surveillance would be the initial step. ${ }^{28,29}$ In this cohort, the proportion of males who underwent surveillance is similar to the overall cohort and the gender distribution of this cancer. In our study population, males did have a decreased chance of finding HCC that met Milan criteria based on Chi-square analysis. However, this only remained marginally significant after accounting for other predictive factors through multiple logistic regression. Although the reasons for this are not clear, this is similar to the study by Del Poggio in which male gender was associated with surveillance failure. ${ }^{22}$ Gender differences may also be related to $\mathrm{BMI}$, body habitus and adipose tissue distribution, which would need to be explored further.

Patients with ascites were more likely to be identified with single tumors $\leq 2.0 \mathrm{~cm}$. This may be due to the fluid-solid surface interface, which improves clarity of lesions near the liver surface that would otherwise be obscured by surrounding structures. Interventional radiologists frequently use artificial ascites to better define difficult liver lesions for radiofrequency ablation and this technique has been successful in $>90 \%$ of cases. ${ }^{30,31}$ However, our study is the first to demonstrate the advantage of ascites in detecting small tumors during HCC surveillance.

Several studies have examined ultrasound surveillance in cirrhotic patients, but few have evaluated cirrhosis as a risk factor for surveillance failure. In this study, the presence of moderate or severe cirrhosis was associated with improved detection of cases with largest tumor $\leq 3.0 \mathrm{~cm}$, after accounting for demographics and other risk factors. The sensitivity to detect these cases however, was similar to the pooled sensitivity of $63 \%$ as described in a meta-analysis by Singal, et al, evaluating ultrasound surveillance in cirrhotic patients. ${ }^{21}$ As cirrhotic patients already comprise the majority of the at-risk population, it is unclear whether the presence of cirrhosis should impact surveillance.

Failure of US-based surveillance is frequently deemed "operator-dependent" with various implications regarding the experience of the technician or site of the study, i.e. large tertiary/ academic center with liver expertise versus a community or private imaging unit. ${ }^{10,32}$ We have attempted to address this by using Oahu versus non-Oahu as a proxy for an urban versus rural setting for performance of ultrasound. In Hawaii, 75\% of the population and the largest medical centers are located on Oahu. The non-Oahu islands have smaller community hospitals and gastroenterologists, but no specialized centers or hepatologists. Despite these differences, we demonstrated no signifi- 
cant difference in US detection in these two locations.

This study is limited in that it was retrospective and there was no uniform surveillance protocol utilized. US was performed by multiple hospital-based and private imaging centers likely with variable experience and expertise. Although 6 months was the recommended interval, many patients had studies performed within 6-11 months likely due to scheduling, convenience and missed appointments. Many of these studies were performed by technicians who select certain images to be reviewed by the radiologist who is reporting the official interpretation. In these settings, there may be little comment on the quality of the study or particular difficulties encountered in the report. This study also did not address the specific tumor location, as tumors at the dome of the liver near the diaphragm may be more difficult to detect. Although AFP is not universally recommended as a component of surveillance, AFP performed within 2 weeks of the time of surveillance was included in this study. Due to the variable nature of community application of surveillance recommendations, prior AFP values were not consistently available. We would have hoped that an elevated AFP from earlier surveillance US would have prompted additional imaging but this study could not determine this.

Despite the lack of a standard protocol for ultrasound surveillance, each patient in this study underwent ultrasonography in the 12 months prior to the study that diagnosed HCC, which reflects the real world application of ultrasound surveillance. These studies were often ordered by community physicians, performed in multiple settings and with imperfect patient compliance with a 6 -month regimen. Unlike previous studies, our study was also able to address the possibility of differences between US performed in an urban versus rural setting as demonstrated in our comparison of an Oahu versus non-Oahu location. Furthermore, data was prospectively collected over a period of 23 years by the only referral center for liver disease in the Pacific Basin and included a large number of patients. This study also sampled an ethnically diverse population, which contrasts other studies that sampled predominantly Caucasian or Asian populations.

In conclusion, this study demonstrates that surveillance with US appears to be reasonably effective at detecting HCC in patients who have tumors that meet Milan criteria but may be less reliable in small tumors, males and the morbidly obese and better in patients with ascites. Other factors such as age, etiology of disease, diabetes, smoking and location of the ultrasound center did not affect the ability of US to detect HCC.
US is likely sufficient for patients with ascites who are awaiting liver transplant but other strategies may be necessary to adequately detect HCC in patients with obesity. Finally, this study identifies potential areas for improvement and future study of HCC surveillance. Perhaps rather than accept the repeated claim that "Ultrasound is operator-dependent", we should refer only the optimal candidates for US surveillance and develop a metric for determining the quality of the US at a particular center based on their ability to successfully identify HCC with surveillance.

\section{Author contributions}

Wong LL: Conducting the study, collecting data, drafting the manuscript.

Reyes R: Data interpretation, drafting the manuscript.

Kwee S: Drafting the manuscript.

Hernandez BY: Interpreting the data, drafting the manuscript.

Kalathil S: Drafting the manuscript.

Tsai N: Drafting the manuscript.

\section{Acknowledgements}

We would like to acknowledge So Yung Choi and the John A. Burns School of Medicine Biostatistics Core for their role in biostatistical analysis.

\section{Funding support}

Biostatistics support was funded by the RMATRIX-II Grant Award \#U54MD007584.

\section{Conflicts of Interest}

The authors have no conflicts to disclose.

\section{REFERENCES}

1. Ferlay J, Soerjomataram I, Ervik M, Dikshit R, Eser S, Mathers C, et al. GLOBOCAN 2012 v1.0, Cancer Incidence and Mortality Worldwide: IARC CancerBase No. 11. International Agency for Research on Cancer; 2013. World Health Organization web site, <http://globocan.iarc.fr>. Accessed on 2016.08.01.

2. Ryerson $A B$, Eheman $C R$, Altekruse SF, Ward JW, Jemal A, Sherman RL, et al. Annual Report to the Nation on the Status of Cancer, 1975-2012, featuring the increasing incidence of liver cancer. Cancer 2016;122:1312-1337.

3. Howlader N, Noone AM, Krapcho M, Miller D, Bishop K, Altekruse SF, et al. SEER Cancer Statistics Review, 1975-2013, based on 
November 2015 SEER data submission. National Cancer Institute. SEER web site, <http://seer.cancer.gov/csr/1975_2013/>. Accessed 2016.10.26.

4. Zhang BH1, Yang BH, Tang ZY. Randomized controlled trial of screening for hepatocellular carcinoma. J Cancer Res Clin Oncol 2004;130:417-422.

5. Singal AG, Pillai A, Tiro J. Early detection, curative treatment, and survival rates for hepatocellular carcinoma surveillance in patients with cirrhosis: a meta-analysis. PLoS Med 2014;11:e1001624. doi: 10.1371/journal.pmed.1001624. eCollection 2014.

6. Chalasani N, Horlander JC Sr, Said A, Hoen H, Kopecky KK, Stockberger SM Jr, et al. Screening for hepatocellular carcinoma in patients with advanced cirrhosis. Am J Gastroenterol 1999;94:2988-2993.

7. Bruix J. Sherman M. Management of hepatocellular carcinoma. Hepatology 2005;42:1208-1236.

8. Bruix J, Sherman M; American Association for the Study of Liver Diseases. Management of hepatocellular carcinoma: an update. Hepatology 2011;53:1020-1022.

9. Davila JA, Morgan RO, Richardson PA, Du XL, McGlynn KA, El-Serag HB. Use of surveillance for hepatocellular carcinoma among patients with cirrhosis in the United States. Hepatology 2010;52:132-141.

10. Finberg HJ. Whither (wither?) the ultrasound specialist? J Ultrasound Med 2004;23:1543-1547.

11. United Network for Organ Sharing. Policy 3.6.4.4. at <www.optn. transplant.hrsa.gov>. Accessed 2009.05.20.

12. Edge SB, Byrd DR, Compton CC, Fritz AG, Greene FL, Trotti A. AJCC cancer staging manual. 7th ed. New York: Springer, 2009:191-199.

13. Wong LL, Limm WM, Severino R, Wong LM. Improved survival with screening for hepatocellular carcinoma. Liver Transplant 2000;6:320-325.

14. Chen THH, Chen CJ, Yen MF, Lu SN, Sun CA, Huang GT, et al. Ultrasound screening and risk factors for death from hepatocellular carcinoma in a high risk group in Taiwan. Int J Cancer 2002;98:257-261.

15. Yeh YP, Hu TH, Cho PY, Chen HH, Yen AM, Chen SL, et al. Evaluation of abdominal ultrasonography mass screening for hepatocellular carcinoma in Taiwan. Hepatology 2014;59:1840-1849.

16. Trevisani F, De Notariis $S$, Rapaccini G, Farinati F, Benvegnù L, Zoli $M$, et al. Semiannual and annual surveillance of cirrhotic patients for hepatocellular carcinoma: effects on cancer stage and patient survival (Italian experience). Am J Gastroenterol 2002;97:734-744.

17. El-Serag HB. Hepatocellular Carcinoma. N Engl J Med 2011;365:11181127.

18. Tanaka H, Nouso K, Kobashi H, Kobayashi Y, Nakamura S, Miyake $Y$, et al. Surveillance of hepatocellular carcinoma in patients with hepatitis C virus infection may improve patient survival. Liver Int 2006;26:543-551.

19. Wong GL, Wong VW, Tan GM, Ip KI, Lai WK, Li YW, et al. Surveil- lance programme for hepatocellular carcinoma improves the survival of patients with chronic viral hepatitis. Liver Int 2007;28:79-87.

20. Tong MJ, Sun HE, Hsien C, Lu DS. Surveillance for hepatocellular carcinoma improves survival in Asian-American patients with hepatitis $B$ : results from a community-based clinic. Dig Dis Sci 2010;55:826-835.

21. Singal A, Volk ML, Waljee A, Salgia R, Higgins P, Rogers MA, et al. Meta-analysis: surveillance with ultrasound for early-stage hepatocellular carcinoma in patients with cirrhosis. Aliment Pharmacol Ther 2009;30:37-47.

22. Del Poggio P, Olmi S, Ciccarese F, Di Marco M, Rapaccini GL, Benvegnù $L$, et al. Factors that affect efficacy of ultrasound surveillance for early stage hepatocellular carcinoma in patients with cirrhosis. Clin Gastroenterol Hepatol 2014;12:1927-1933.e2.

23. Singal AG, Nehra M, Adams-Huet B, Yopp AC, Tiro JA, Marrero JA, et al. Detection of hepatocellular carcinoma at advanced stages among patients in the HALT-C trial: where did surveillance fail? Am J Gastroenterol 2013;108:425-432.

24. Uppot RN, Sahani DV, Hahn PF, Gervais D, Mueller PR. Impact of obesity on medical imaging and image-guided intervention. AJR Am J Roentgenol 2007;188:433-440.

25. Yu NC, Chaudhari V, Raman SS, Lassman C, Tong MJ, Busuttil RW, et al. CT and MRI improve detection of hepatocellular carcinoma, compared with ultrasound alone, in patients with cirrhosis. Clin Gastroenterol Hepatol 2011;9:161-167.

26. Rothman KJ. BMI-related errors in the measurement of obesity. Int J Obes (Lond) 2008;32 Suppl 3:S56-S59.

27. Davila JA, Morgan RO, Shaib Y, McGlynn KA, El-Serag HB. Diabetes increases the risk of hepatocellular carcinoma in the United States: a population based case control study. Gut 2005;54:533-539.

28. Mustard CA, Kaufert P, Kozyrskyj A, Mayer T. Sex differences in the use of health care services. N engl J Med 1998;338:1678-1683.

29. Davis JL, Buchanan KL, Katz RV, Green BL. Gender differences in cancer screening beliefs, behaviors and willingness to participate: implications for health promotion. Am J Mens Health 2012;6:211-217.

30. Kim PN, Choi D, Rhim H, Rha SE, Hong HP, Lee J, et al. Planning ultrasound for percutaneous radiofrequency ablation to treat small $(\leq 3$ $\mathrm{cm}$ ) hepatocellular carcinomas detected on computed tomography or magnetic resonance imaging: a multicenter prospective study to assess factors affecting ultrasound visibility. J Vasc Interv Radiol 2012;23:627-634.

31. Rhim H, Lim HK. Radiofrequency ablation for hepatocellular carcinoma abutting the diaphragm: the value of artificial ascites. Abdom Imaging 2009;34:371-380.

32. Singal AG, Yopp AC, Gupta S, Skinner CS, Halm EA, Okolo E, et al. Failure rates in the hepatocellular carcinoma surveillance process. Cancer Prev Res (Phila) 2012;5:1124-1130. 